\title{
Three-dimensional Assessment of the Breast: Validation of a Novel, Simple and Inexpensive Scanning Process
}

\author{
CARLO M. ORANGES ${ }^{1}$, SRINIVAS MADDURI $^{1,2,3}$, PHILIPP BRANTNER $^{4}$, \\ BILAL MSALLEM $^{4,5}$, SALVATORE GIORDANO ${ }^{6}$, BENITO BENITEZ $^{4,5}$, \\ DANIEL F. KALBERMATTEN ${ }^{1}$, DIRK J. SCHAEFER ${ }^{1}$ and FLORIAN M. THIERINGER ${ }^{4,5}$ \\ ${ }^{1}$ Department of Plastic, Reconstructive, Aesthetic, and Hand Surgery, \\ Basel University Hospital, University of Basel, Basel, Switzerland; \\ ${ }^{2}$ Department of Biomedicine, University of Basel, Basel, Switzerland; \\ ${ }^{3}$ Department of Biomedical Engineering, University of Basel, Basel, Switzerland; \\ ${ }^{4}$ Medical Additive Manufacturing Research Group, Department of Biomedical Engineering, \\ University of Basel, Allschwil, Switzerland; \\ ${ }^{5}$ Department of Oral and Cranio-Maxillofacial Surgery, Basel University Hospital, Basel, Switzerland; \\ ${ }^{6}$ Department of Plastic and General Surgery, Turku University Hospital, University of Turku, Turku, Finland
}

\begin{abstract}
Background/Aim: Methods to assess threedimensionally the breast surface are increasingly used in plastic and reconstructive surgery. The aim of this study was to validate the use of the Structure Sensor $3 D$ scanner (Occipital, Inc., Boulder, CO, USA) connected to an iPad Pro (Apple, Inc., Cupertino, CA, USA) as a novel, inexpensive and handheld three-dimensional scanning process. Materials and Methods: Surface images of a medical human female anatomy torso model of rigid plastic were repeatedly acquired with Structure Sensor $3 D$ scanner and compared with those obtained using two clinically established $3 D$ imaging systems. Digital measurements of vector and surface breast distances were analyzed using Mimics ${ }^{\circledR}$ Innovation Suite 20 medical imaging software (Materialise, Leuven, Belgium). Results: The analysis of variance (ANOVA) revealed no statistically significant difference among measurements obtained using different scanning processes for all the variables examined $(p>0.05)$. Conclusion: The study demonstrates analogous
\end{abstract}

This article is freely accessible online.

Correspondence to: Carlo M. Oranges, MD, Department of Plastic, Reconstructive, Aesthetic, and Hand Surgery, Basel University Hospital, Spitalstrasse 21, 4031 Basel, Switzerland. Tel: +41 612652525, Fax: +41 612657301, e-mail: carlo.oranges@usb.ch or Florian M. Thieringer, MD, DDS, MHBA, Department of Oral and Cranio-Maxillofacial Surgery, Basel University Hospital, Spitalstrasse 21, 4031 Basel, Switzerland. Tel: +41 612657344, Fax: +41 612657298, e-mail: florian.thieringer@usb.ch

Key Words: 3D scanning, three-dimensional, surface imaging, photogrammetry, virtual surgical planning. practicability and reliability for surface image acquisition using the newly introduced Structure Sensor 3D scanner and other clinically established scanners.

Three-dimensional photographic imaging technologies are gaining an increasing role in plastic and reconstructive surgery. They allow accurate and efficient pre-operative analysis to formulate diagnosis and establish endpoint goals of treatment to address the underlying morphology and, thus, prepare an appropriate surgical plan (1).

Furthermore, in contrast to traditional two-dimensional photography, three-dimensional imaging is growingly regarded as a fundamental tool to objectively measure outcomes by providing true surface anatomy (2). Notably, volumetric and geometric parameters analyses such as depth and surface topographic distance measurements can also be performed, yielding important additional data (2).

These elements are considered particularly relevant in case of breast surgery, where they can be used to evaluate symmetry, surface and volumetric changes, including total breast volumes, volumetric distribution, and breast projection. Moreover, surface and vector measurements can be assessed to define breast contour, size, and position on the chest wall (3).

A number of researches have indeed validated the use of three-dimensional imaging in the clinical context of autologous or prosthetic breast reconstruction, and breast augmentation and reduction (3-10). Several validated devices are available for three-dimensional breast images capturing. However, many of them are not portable, heavyweight and generally expensive (11). These characteristics make them of unpractical use in the daily practice. 
We previously described the use of a novel, simple and inexpensive three-dimensional scanning system for breast surface evaluation (12). The aim of this study was to validate its use in comparison to other clinically established threedimensional imaging systems.

\section{Materials and Methods}

We performed a scanning process using the Structure Sensor 3D scanner (Occipital, Inc., Boulder, CO, USA) connected to an iPad Pro (Apple, Inc., Cupertino, CA, USA), available at a price of 379 USD. The device is a structured/infrared light handheld scanner that measures 11.92 (width) $\times 2.9$ (height) $\times 2.8$ (depth) $\mathrm{cm}$ and has a weight of $95 \mathrm{~g}$.

The established Vectra M5 Scanner (Canfield Scientific Inc., Parsippany, NJ, USA) 3D imaging system and Artec Eva 3D scanner (Artec3D, Luxembourg, Luxembourg) were used as a reference. The former is a stationary passive stereophotogrammetrybased system, while the latter is a handled structured light threedimensional scanning system that measures 26.1 (width) $\times 15.8$ (height) $x 6.3$ (depth) $\mathrm{cm}$ and has a weight of $850 \mathrm{~g}$. The last two devices are marketed at a higher price of over 10,000 USD.

The tree-dimensional scans were acquired, with all systems, on a medical human female anatomy torso model of rigid plastic in a room with normal illumination. The torso was scanned five times with each device. All scans were imported into the Mimics ${ }^{\circledR}$ Innovation Suite 20 medical imaging software (Materialise, Leuven, Belgium) to obtain from the three-dimensional images the following clinical measurements of each breast: sternal notch-to-nipple distance (S-N); nipple-to-inframammary fold distance (N-I); lateral inframammary fold-to-medial inframammary fold distance (L-M); upper pole-to-inframammary fold distance (U-I). All these distances were calculated both as a surface measurement and as a direct vector measurement. The vector distance between the two nipples $(\mathrm{N}-\mathrm{N})$ was also measured.

Furthermore, a single computer tomographic (CT) scan of the torso was also acquired and analyzed through the Mimics ${ }^{\circledR}$ Innovation Suite 20 medical imaging software (Materialise, Leuven, Belgium) as objective reference of the actual values of the measurements.

The analysis of variance (ANOVA) test was performed to determine if the differences among measurements obtained using different scanning processes were significant. Statistical significance was defined as $p<0.05$. All statistical analyses were performed using the SPSS ${ }^{\circledR}$ Advanced Statistical TM software package (ver. 13; SPSS Inc., Chicago, IL, USA).

\section{Results}

We calculated the landmark-based vector and surface distances. No statistically significant difference $(p>0.05)$ was found with regard to all mean distances measured on the three-dimensional images captured using Structure Sensor 3D scanner, Vectra M5 scanner or Artec Eva 3D scanner. Moreover, no statistically significant difference was found in comparison to the images obtained using the CT scanner $(p>0.05)$, with the only exception of the N-I surface distance of the left breast.

In detail, the following results were observed with regard to vector distances: mean L-M distance was equal in the right and left breast for each scanner with the exception of the CT scan, and ranged between $129.56 \mathrm{~mm}(\mathrm{SD}=0.40)$ measured with Vectra M5 scanner and $130.07 \mathrm{~mm}(\mathrm{SD}=1.34)$ measured with Artec Eva 3D scanner, with no statistical difference $(p=0.77$ in the right breast and $p=0.75$ in the left breast); mean $\mathrm{S}-\mathrm{N}$ distance ranged between $179.07 \mathrm{~mm}(\mathrm{SD}=1.06)$ and $179.77 \mathrm{~mm}$ ( $\mathrm{SD}=0.78)$ in the right breast $(p=0.43)$ and between $175.97 \mathrm{~mm}$ $(\mathrm{SD}=0.85)$ and $176.41 \mathrm{~mm}(\mathrm{SD}=1.22)$ in the left breast $(p=0.67)$; mean N-I distance ranged between $69.18 \mathrm{~mm}$ $(\mathrm{SD}=0.51)$ and $69.79 \mathrm{~mm}(\mathrm{SD}=0.41)$ in the right breast $(p=0.35)$ and between $69.45 \mathrm{~mm}(\mathrm{SD}=0.38)$ and $70.03 \mathrm{~mm}$ $(\mathrm{SD}=0.83)$ in the left breast $(p=0.42)$; mean U-I distance ranged between $167.64 \mathrm{~mm}(\mathrm{SD}=0.68)$ and $168.11 \mathrm{~mm}(\mathrm{SD}=0.24)$ in the right breast $(p=0.34)$ and between $166.07 \mathrm{~mm}(\mathrm{SD}=0.12)$ in the left breast $(p=0.20)$. Finally, the mean N-N vector distance ranged between $195.94 \mathrm{~mm}(\mathrm{SD}=0.44)$ and $196.57 \mathrm{~mm}$ $(\mathrm{SD}=1.88)$, with no statistically significant difference $(p=0.72)$.

The detailed results regarding surface distances analysis are the following: mean L-M distance ranged between $187.81 \mathrm{~mm}$ $(\mathrm{SD}=1.25)$ and $189.30 \mathrm{~mm}(\mathrm{SD}=0.99)$ in the right breast $(p=0.1)$ and between $185.44 \mathrm{~mm}(\mathrm{SD}=0.49)$ and 185.58 $(\mathrm{SD}=0.61)$ in the left breast $(p=0.8)$; mean $\mathrm{S}-\mathrm{N}$ distance ranged between $179.99 \mathrm{~mm}(\mathrm{SD}=0.45)$ and $180.80 \mathrm{~mm}$ $(\mathrm{SD}=0.77)$ in the right breast $(p=0.1)$ and between $178.96 \mathrm{~mm}$ $(\mathrm{SD}=0.81)$ and $179.26 \mathrm{~mm}(\mathrm{SD}=0.99)$ in the left breast $(p=0.09)$; mean U-I distance ranged between $196.87 \mathrm{~mm}$ $(\mathrm{SD}=0.35)$ and $197.15 \mathrm{~mm}(\mathrm{SD}=0.30)$ in the right breast $(p=0.45)$ and between $195.40 \mathrm{~mm}(\mathrm{SD}=0.32)$ in the left breast $(p=0.70)$. Finally, the mean surface N-I distance ranged between $69.43 \mathrm{~mm}(\mathrm{SD}=0.31)$ and $69.73 \mathrm{~mm}(\mathrm{SD}=0.44)$ in the right breast $(p=0.40)$ and between $69.39 \mathrm{~mm}(\mathrm{SD}=0.29)$ and $69.64 \mathrm{~mm}(\mathrm{SD}=0.19)$ in the left breast $(p=0.39)$, with no statistically significant difference among the Structure Sensor 3D scanner, Vectra M5 scanner or Artec Eva 3D scanner. However, in this last group, a statistically significant difference was observed with the CT scan images $(p=0.0004)$.

\section{Discussion}

The application of three-dimensional imaging to breast surgery is a fast-developing concept that has been validated to date by a number of studies for both accuracy and reproducibility of the technology (1-9, 13-18). This has been considered particularly useful for the pre-operative planning and post-operative assessment of operations such as breast reconstruction, breast augmentation and breast reduction, as well as for the assessment of fat grafting outcomes where also small volume variations must be considered (3, 19-21). Our aim was to validate the use of an innovative and inexpensive scanning process.

In their comprehensive overview of the topic, Tepper et al. introduced the concept of mammometrics, defined as the establishment of fixed planes and points on three-dimensional 
images to perform objective breast measurements (3). We calculated vectors and surface distances among landmarks of the breast and bony anatomical landmarks of the torso that represent important clinical measurements. The difference among the distances obtained using Structure Sensor and the established Vectra M5 scanner and Artec Eva 3D scanner, that was not found to be statistically significant, allowed us to validate the new scanning process.

The reasons for comparing Structure Sensor with Vectra M5 scanner and Artec Eva 3D scanner are based on the already validated use of these devices. In particular, Vectra technology has been used to capture face, neck, breast and body (13) while the clinical use of Artec Eva 3D has been described for the surface assessment of face, torso, upper and lower extremity (22-29). All three scanning processes showed consistent results also in comparison with the CT scanning, with only one exception, further demonstrating their accuracy.

A previous research compared the use of Structure Sensor and VECTRA ${ }^{\circledR} \mathrm{XT}$ (Canfield Scientific, NJ, USA) 3D camera system, reaching the similar conclusion that Structure Sensor offers sufficient three-dimensional imaging quality to measure breast distances and volumes (11). In comparison with this research, which was performed in female breast patients, we decided to perform our measurements by using a medical human female anatomy torso model of rigid plastic in order to reduce the possible biases related to the need of ensuring the correct positioning of the patients or artifacts from highly moveable areas. Moreover, our results were also confronted with those obtained with Artec Eva 3D and CT scanners, ensuring a high level of objectivity.

The advantages of the use of Structure Sensor are certainly the portability, easy handleability and the low cost. However, both Vectra M5 and Artec Eva 3D solutions offer advanced software applications which are able to support the analysis of the three-dimensional images. For this purpose, the alternative use of an open access software such as MeshLab 2016 is possible but more complex and requires higher levels of training.

Overall, these findings are particularly important for their applications in the continuously evolving research in the field of breast and body contouring surgeries for both reconstructive and aesthetic purposes (30-36).

In conclusion, this research was able to validate the use of Structure Sensor 3D scanner (Occipital, Inc., Boulder, CO, USA) for breast surface assessment. However, further research in this area is needed to develop standardized procedures that can be used in the daily plastic and reconstructive surgery practice.

\section{Conflicts of Interest}

There are no conflicts of interest regarding this study.

\section{Authors' Contributions}

Study design: Carlo M. Oranges, Florian M. Thieringer, Philipp Brantner, Daniel F. Kalbermatten, Dirk J. Schaefer; Data acquisition and collection: Carlo M. Oranges, Florian M. Thieringer, Benito Benitez, Bilal Msallem; Statistical analysis: Carlo M. Oranges, Srinivas Madduri, Salvatore Giordano; Manuscript drafting: Carlo M. Oranges. Critical revision: all Authors. Final approval: all Authors.

\section{References}

1 Pfaff MJ and Steinbacher DM: Plastic surgery applications using three-dimensional planning and computer-assisted design and manufacturing. Plast Reconstr Surg 137: 603e-616e, 2016. PMID: 26910704. DOI: 10.1097/01.prs.0000479970.22181.53

2 Weissler JM, Stern CS, Schreiber JE, Amirlak B and Tepper OM: The evolution of photography and three-dimensional imaging in plastic surgery. Plast Reconstr Surg 139: 761-769, 2017. PMID: 28234862. DOI: 10.1097/PRS.0000000000003146

3 Tepper OM, Unger JG, Small KH, Feldman D, Kumar N, Choi $M$ and Karp NS: Mammometrics: the standardization of aesthetic and reconstructive breast surgery. Plast Reconstr Surg 125: 393-400, 2010. PMID: 20048631. DOI: 10.1097/ PRS.0b013e3181c4966e

4 Tepper OM, Small KH, Unger JG, Feldman DL, Kumar N, Choi $M$ and Karp NS: 3D analysis of breast augmentation defines operative changes and their relationship to implant dimensions. Ann Plast Surg 62: 570-575, 2009. PMID: 19387164. DOI: 10.1097/SAP.0b013e31819faff9

5 Tepper OM, Small K, Rudolph L, Choi M and Karp N: Virtual 3-dimensional modeling as a valuable adjunct to aesthetic and reconstructive breast surgery. Am J Surg 192: 548-551, 2006. PMID: 16978973. DOI: 10.1016/j.amjsurg.2006.06.026

6 Tepper OM, Choi M, Small K, Unger J, Davidson E, Rudolph L, Pritchard A and Karp NS: An innovative three-dimensional approach to defining the anatomical changes occurring after short scar-medial pedicle reduction mammaplasty. Plast Reconstr Surg 121: 1875-1885, 2008. PMID: 18520872. DOI: 10.1097/ PRS.0b013e31817151db

7 Losken A, Seify H, Denson DD, Paredes AA Jr and Carlson GW: Validating three-dimensional imaging of the breast. Ann Plast Surg 54: 471-476, 2005. PMID: 15838205. DOI: 10.1097/ 01.sap.0000155278.87790.a1

8 Kovacs L, Yassouridis A, Zimmermann A, Brockmann G, Wöhnl A, Blaschke M, Eder M, Schwenzer-Zimmerer K, Rosenberg R, Papadopulos NA and Biemer E: Optimization of 3-dimensional imaging of the breast region with 3-dimensional laser scanners. Ann Plast Surg 56: 229-236, 2006. PMID: 16508349. DOI: 10.1097/01.sap.0000197774.80832.24

9 Isogai N, Sai K, Kamiishi H, Watatani M, Inui H and Shiozaki H: Quantitative analysis of the reconstructed breast using a 3dimensional laser light scanner. Ann Plast Surg 56: 237-242, 2006. PMID: 16508350. DOI: 10.1097/01 sap.0000200716.82945.b2

10 Choi M, Unger J, Small K, Tepper O, Kumar N, Feldman D and Karp N: Defining the kinetics of breast pseudoptosis after reduction mammaplasty. Ann Plast Surg 62: 518-522, 2009. PMID: 19387153. DOI: $10.1097 /$ SAP.0b013e31819fb00c

11 Koban KC, Härtnagl F, Titze V, Schenck TL and Giunta RE: Chances and limitations of a low-cost mobile 3D scanner for breast imaging in comparison to an established 3D photogrammetric 
system. J Plast Reconstr Aesthet Surg 71: 1417-1423, 2018. PMID: 29970344. DOI: 10.1016/j.bjps.2018.05.017

12 Oranges CM, Thieringer FM, Kalbermatten DF, Haug M and Schaefer DJ: The evolution of photography and three-dimensional imaging in plastic surgery. Plast Reconstr Surg 141: 196e-197e, 2018. PMID: 28938370. DOI: 10.1097/PRS.0000000000004005.

13 Tzou CH, Artner NM, Pona I, Hold A, Placheta E, Kropatsch WG and Frey M: Comparison of three-dimensional surfaceimaging systems. J Plast Reconstr Aesthet Surg 67: 489-497, 2014. PMID: 24529695. DOI: 10.1016/j.bjps.2014.01.003

14 Chang JB, Small KH, Choi M and Karp NS: Three-dimensional surface imaging in plastic surgery: foundation, practical applications, and beyond. Plast Reconstr Surg 135: 1295-304, 2015. PMID: 25835245. DOI: 10.1097/PRS .0000000000001221

15 Chae MP, Rozen WM, Spychal RT and Hunter-Smith DJ: Breast volumetric analysis for aesthetic planning in breast reconstruction: a literature review of techniques. Gland Surg 5: 212-226, 2016. PMID: 27047788. DOI: 10.3978/j.issn.2227684X.2015.10.03

16 Donfrancesco A, Montemurro P and Heden P: Three-dimensional simulated images in breast augmentation surgery: an investigation of patients' satisfaction and the correlation between prediction and actual outcome. Plast Reconstr Surg 132: 810-822, 2013. PMID: 24076673. DOI: 10.1097/PRS. 0b013e3182a014cb

17 Epstein MD and Scheflan M: Three-dimensional imaging and simulation in breast augmentation: what is the current state of the art? Clin Plast Surg 42: 437-450, 2015. PMID: 26408435. DOI: $10.1016 /$ j.cps.2015.06.013

18 de Runz A, Boccara D, Bertheuil N, Claudot F, Brix M and Simon E: Three-dimensional imaging, an important factor of decision in breast augmentation. Ann Chir Plast Esthet 63: 134139, 2018. PMID: 28911890. DOI: 10.1016/j.anplas.2017.07.019

19 Oranges CM, Striebel J, Tremp M, Madduri S, Kalbermatten DF and Schaefer DJ: The impact of recipient site external expansion in fat grafting surgical outcomes. Plast Reconstr Surg Glob Open 6: e1649, 2018. PMID: 29616164. DOI: 10.1097/GOX.0000 000000001649

20 Oranges CM, Tremp M, Ling B, Wettstein R, Largo RD and Schaefer DJ: A simple, reliable, and inexpensive intraoperative external expansion system for enhanced autologous structural fat grafting. Arch Plast Surg 43: 466-469, 2016. PMID: 27689056. DOI: $10.5999 /$ aps.2016.43.5.466

21 Oranges CM and Schaefer DJ: The use of autologous fat grafting for treatment of scar tissue and scar-related conditions: A Systematic Review. Plast Reconstr Surg 138: 551e-552e, 2016. PMID: 27140039. DOI: 10.1097/PRS.0000000000002441

22 Koban KC, Titze V, Etzel L, Frank K, Schenck T and Giunta R: Quantitative volumetric analysis of the lower extremity: validation against established tape measurement and water displacement. Handchir Mikrochir Plast Chir 50: 393-399, 2018. PMID: 30620977. DOI: 10.1055/a-0770-3445

23 Grant CA, Johnston M, Adam CJ and Little JP: Accuracy of 3D surface scanners for clinical torso and spinal deformity assessment. Med Eng Phys 63: 63-71, 2019. PMID: 30467027. DOI: $10.1016 /$ j.medengphy.2018.11.004

24 Koban KC, Cotofana S, Frank K, Green JB, Etzel L, Li Z, Giunta RE and Schenck TL: Precision in 3-Dimensional surface imaging of the face: a handheld scanner comparison performed in a cadaveric model. Aesthet Surg J, 2018. PMID: 30239592. DOI: $10.1093 / \mathrm{asj} / \mathrm{sjy} 242$
25 Verhulst A, Hol M, Vreeken R, Becking A, Ulrich D and Maal T: Three-Dimensional Imaging of the Face: A comparison between three different imaging modalities. Aesthet Surg J 38: 579-585, 2018. PMID: 29360971. DOI: 10.1093/asj/sjx 227

26 Seminati E, Canepa Talamas D, Young M, Twiste M, Dhokia V and Bilzon JLJ: Validity and reliability of a novel 3D scanner for assessment of the shape and volume of amputees' residual limb models. PLoS One 12: e0184498, 2017. PMID: 28886154. DOI: 10.1371/journal.pone.0184498

27 Modabber A, Peters F, Brokmeier A, Goloborodko E, Ghassemi A, Lethaus B, Hölzle F and Möhlhenrich SC: Influence of connecting two standalone mobile three-dimensional scanners on accuracy comparing with a standard device in facial scanning. J Oral Maxillofac Res 7: e4, 2016. PMID: 28154748. DOI: 10.5037/jomr.2016.7404

28 Yamamoto S, Miyachi H, Fujii H, Ochiai S, Watanabe S and Shimozato K: Intuitive facial imaging method for evaluation of postoperative swelling: a combination of 3-dimensional computed tomography and laser surface scanning in orthognathic surgery. J Oral Maxillofac Surg 74: 2506.e1-2506.e10, 2016. PMID: 27669371. DOI: 10.1016/j.joms.2016.08.039

29 Modabber A, Peters F, Kniha K, Goloborodko E, Ghassemi A, Lethaus B, Hölzle F and Möhlhenrich SC: Evaluation of the accuracy of a mobile and a stationary system for threedimensional facial scanning. J Craniomaxillofac Surg 44: 17191724, 2016. PMID: 27614543. DOI: 10.1016/j.jcms.2016.08.008

30 Amabile MI, Mazouni C, Guimond C, Sarfati B, Leymarie N, Cloutier AS, Bentivegna E, Garbay JR, Kolb F and Rimareix F: Factors predictive of re-excision after oncoplastic breast-conserving surgery. Anticancer Res 35: 4229-4234, 2015. PMID: 26124383.

31 Munhoz AM, Montag E, Filassi JR and Gemperli R: Current approaches to managing partial breast defects: the role of conservative breast surgery reconstruction. Anticancer Res 34: 1099-1114, 2014. PMID: 24596348.

32 Gabka CJ, Baumeister RG and Maiwald G: Advancements of breast conserving therapy by onco-plastic surgery in the management of breast cancer. Anticancer Res 18: 2219-2224, 1998. PMID: 9703788.

33 Gigli S, Amabile MI, DI Pastena F, DE Luca A, Gulia C, Manganaro L, Monti $\mathrm{M}$ and Ballesio L: Lipofilling outcomes mimicking breast cancer recurrence: case report and update of the literature. Anticancer Res 37: 5395-5398, 2017. PMID: 28982848. DOI: 10.21873 /anticanres.11966

34 Tremp M, di Summa PG, Schaakxs D, Oranges CM, Wettstein $\mathrm{R}$ and Kalbermatten DF: Nipple reconstruction after autologous or expander breast reconstruction: a multimodal and 3Dimensional analysis. Aesthet Surg J 37: 179-187, 2017. PMID: 27986753. DOI: $10.1093 /$ asj/sjw 181

35 Oranges CM, Haug M and Schaefer DJ: Body Contouring. Plast Reconstr Surg 138: 944e-945e, 2016. PMID: 27391823. DOI: 10.1097/PRS.0000000000002724

36 di Summa PG, Oranges CM, Wafta W, Sapino G, Keller N, Tay SK, Chew BK, Schaefer DJ and Raffoul W: Systematic review of outcomes and complications in nonimplant-based mastopexy surgery. J Plast Reconstr Aesthet Surg 72: 243-272, 2019. PMID: 30527707. DOI: 10.1016/j.bjps.2018.10.018

Received February 13, 2019

Revised March 5, 2019

Accepted March 6, 2019 